\title{
A Path Analytic Model Exploration of Determinants of Happiness of Older Adults in Abu Dhabi
}

\author{
Muna Al Bahar ${ }^{1,2} \cdot$ Masood Badri ${ }^{1,3} \cdot$ Mugheer Al Khaili $^{3} \cdot$ Fahad Al Neyadi $^{2}$. \\ Guang Yang ${ }^{2}$. Asma Al Rashdi ${ }^{2}$
}

Accepted: 26 July 2021 / Published online: 7 September 2021

(c) The Author(s) 2021

\begin{abstract}
The objective of the study was to identify the factors associated with the subjective well-being of older adults in Abu Dhabi when happiness is taken as the dependent variable. In the present research, a framework based on theoretical models was developed in which older adult's happiness was seen in a synergistic relationship and was associated with many other variables related to various domains in the social system. The sample consisted of 1,004 older adults aged 60 and above, who participated in the First Abu Dhabi General Social Survey administered in 2018. Many subjective well-being variables were considered. Path analysis was used to develop a model that incorporated the five following variables directly affecting the happiness of older adults: housing satisfaction, satisfaction with family life, satisfaction with friendships, life satisfaction, satisfaction with surrounding environment, and some psychological feelings. The study highlighted all direct and indirect associations. Further analysis of variance revealed the associations of gender, marital status, and education attainment. Implications of the study were highlighted along with future research directions.
\end{abstract}

Keywords Older adults · Well-being · Happiness · Life satisfaction · Abu Dhabi

\section{Introduction}

Promoting the subjective well-being (SW) of older adults through different means to enhance their satisfaction with life and happiness has represented a challenge for public policy makers and other professionals in the fields of health, income, environment, and social development (Lima et al., 2012; Parra-Rizo and Sanchis-Soler, 2020). Like many other countries, aging has become an urgent social concern in Abu Dhabi, the United Arab Emirates (UAE) and is particularly relevant for overall

Masood Badri

Masood.Badri@adek.AbuDhabi.ae

Extended author information available on the last page of the article 
social development policies. In this regard, attention to older adults has attracted public attention, especially in terms of happiness and quality of life (QOL). There is a growing consensus that older adults related care goes way beyond merely maintaining the physical health of older adults, it is also about maintaining their overall well-being. Therefore, research on happiness and QOL for Abu Dhabi's older adults becomes relevant. Taking happiness and QOL as the central focus, this research is set to understand a set of comprehensive indicators that measure the current situations of older adults' lives.

The Abu Dhabi General Social Survey (ADGSS) was administered by the Abu Dhabi Department of Community Development in 2018. The survey was developed based on many international surveys such as the Organization for Economic Cooperation and Development's (OECD) Better Life Index, with an objective to collect information to assess the trends in the well-being and QOL of adults against a background of the changing social and economic landscape of Abu Dhabi society. The survey provided an overview of multiple dimensions that examined subjective wellbeing such as happiness and life satisfaction, optimism, health, standard of living, work-life balance, public services, social security, perceptions of social belonging, social challenges, trust in people and institutions, civic participation and community engagement, and other aspects of social well-being. The Abu Dhabi Department of Community Development's framework for measuring well-being incorporated input from a variety of other national and international initiatives for measuring the progress of societies. Conceptually, the framework reflected elements of the capabilities approach (Anand et al., 2011), with many dimensions addressing factors that can expand adults' choices and opportunities to live the lives that they value.

In the current social context, this study attempts to provide a holistic model identifying most significant variables associated with happiness of the older adults in Abu Dhabi. Taking happiness as the main dependent variable, the study aims to construct a model where the relationships between all variables and the direction between them are specifically laid out. Many processes are followed to clearly illustrate the various complex and hypothesized relationships. The study allows for the analysis and examination of situations in which several variables and chains of influence interact.

This research contributes to the body of literature in several ways. First, we provide an analysis of the determinants of happiness for Abu Dhabi's older adults taking into consideration a variety of well-being factors. Second, we provide insights for policy makers and professionals to enhance their understandings of the lives of Abu Dhabi's older adults. Third, our results could be used as insider intelligence for creating programs to promote and provide suitable services to enhance the happiness of the older adults.

\section{Review of Literature}

In the literature, the concept of SW often refers to a few different but related constructs such as happiness, life satisfaction, and QOL (Bakker and Oerlemans, 2011; Massey et al., 2020). According to the multiple discrepancy theory, the effect of 
various objective conditions is mediated by psychological processes through which adults adjust to up and downs in their life and circumstances (Tellaa et al., 2010). Some researchers note that SW reflects positive emotions much more than negative emotions (Diener et al., 2009). Myers (2013) also stresses that SW reflects more self-perceived happiness or satisfaction with life. With regard to older adults, rather than concentrating on objective conditions, some researchers propose frameworks in which objective conditions are replaced by subjective reports on the satisfaction adults expressed with those conditions (Campbell, 1981; Farahani et al., 2020). In such frameworks, happiness or overall satisfaction with life is the net outcome of subjective satisfaction with important domains of life (Gao, 2018).

In the social gerontological literature, happiness is considered the main indicator of SW (George, 1979). Stock et al. (1986) defines happiness as the net of positive over negative affect, accumulated and assessed over all life domains. In the current context, happiness reflects how much one likes the life he lives, or the degree to which one evaluates his life as a whole positively. Happiness depends on both cognitive and emotional components (Saricam, 2005). Usually, adults assess how well they meet their own standards of good life (Pavot and Diener, 2008) and how well they feel as reflected by their emotional experience (Diener et al., 2009). Many researchers portray the concept of happiness as psychological happiness focusing on state of mind, and prudential happiness focusing on well-being (Campbell, 1981; Chekola, 2007). Some view happiness as an emotion combined with other positive emotions, resulting in subjective well-being (Brülde, 2007). Others relate it to mood (Lyubomirsky et al., 2005) and focus on the hedonic aspect of the mood (Veenhoven, 2009). Virtually most life domain studies agree on several major domains to have significant importance as predictors of happiness (Cummins, 1996).

Life satisfaction is usually taken as an important factor related to the concept of QOL (Diener et al., 2003). QOL has both objective and subjective dimensions. The objective variables may include the amounts of friendship, income, networks, and access to various services (Valois et al., 2006), while the subjective dimension may include variables such as judgments related to overall life satisfaction or satisfaction from specific life domains (Oishi et al., 1999). Veenhoven (2009) defines life satisfaction as the degree to which a person positively evaluates the overall quality of her/his life as a whole. Researchers have used different dimensions to define life satisfaction. For example, Rey et al. (2011) includes emotional intelligence and selfesteem, while Lucas et al. (1996) includes optimism and frequent positive emotional experiences. Lopez and Rice (2006) notes that subjective happiness is one of life satisfaction indicators that could explain well-being.

\section{The Older Adults and Well-Being}

SW is considered to be one of the important indicators of successful aging (Herero and Extremera, 2010; Veenhoven, 2009). With regard to older adults, a comprehensive literature search suggests the existence of many different factors that affect their SW in general. A brief literature search is performed to identify most important variables. 
Studies of older adults show that assessments of QOL are affected by the person's state of health. Steptoe et al. (2014) notes that happiness and health are closely related and the correlation could become increasingly important at older ages. Physical and mental well-being allows older adults to be exposed to a variety of social interactions as well as some physical exercise (Williamson, 2010). For older adults, SW is also affected by many factors such as material conditions, social and family relationships, and social roles and activities - factors that also change with age (Steptoe et al., 2014). Having meaningful personal relationships is of significant importance for older adults (Williamson, 2010). Personal relationships could be with partner, family and/or friends (Chaudhury and Oswald, 2019). Being engaged in certain activities such as volunteering or participation in cultural activities is important to older adults (Blood and Bamford, 2010). Some studies reveal that older adults are happier when they are more active (Inal et al., 2007). Menec (2003) shows that a greater activity level is positively related to happiness in later life. Accordingly, the existing theoretical frameworks on aging conceptualize retirement as a dynamic process and emphasize the importance of the interaction between various environmental and personal variables unique to each individual (Bye and Pushkar, 2009).

However, the relationship between age and life satisfaction may not be consistent (Myers, 2013). Dolan et al. (2008) finds a U-shaped relationship between age and life satisfaction. Gwozdz and Sousa-Poza (2010) observes the same U-shaped relation but noted a very sharp decline in life satisfaction after age 65 years. Mroczek and Spiro (2005) finds that life satisfaction increases over the years with a peak at age 65 years followed by a decline afterwards. In another study of English men, Steptoe et al. (2014) reveals an inverse U-shaped relationship. Some researchers find a small negative correlation between life satisfaction and age, which is eliminated when factors of poor health, financial problems, and loneliness are controlled for (Blanchflower and Oswald, 2008).

\section{Variables Affecting Happiness and Life Satisfaction}

Research shows that significant predictors of life satisfaction include love, hope, curiosity, zest, gratitude, pleasure, and engagement (Peterson et al., 2007). Other effective variables are socio-demographic variables such as health, education, income, employment, and level of activity participation (Gerstorf et al., 2007). Bishop et al. (2006) hypothesizes that the accumulation of economic resources over time may lead to increased subjective well-being. For older adults, having sufficient financial resources is important to enjoy QOL now and in the future (Tkatch et al., 2018). Research also addresses the link between poverty and health in old age, especially for retired individuals (Blood and Bamford, 2010).

Research on the effect of education on the SW of older adults is not consistent. Pinquart and Sørensen (2000) concludes that education has a small positive effect on well-being. Massey et al. (2020) shows in their study about life satisfaction among older adults in Italy that being educated is positively associated with life satisfaction of men. Kudo et al. (2007) finds that education has no clear effect on older adult's SW. 
Many studies have found a positive relationship between productive activities such as full-time job or volunteering and the well-being of older adults (MorrowHowell et al., 2003). Through analyzing the impact of unemployment on happiness using data from the British Household Panel Study, Clark and Oswald (1994) finds a strong negative relationship between unemployment and mental well-being. Some studies reveal that the relationship between gender and SW is not significant (Cheng and Chan, 2006).

Social support or interaction within a social network of family members and friends plays a major role in SW. Dong et al. (2020) suggests that social support for older adults might involve the reinforcement and exchange of social assistance and support along with social network interaction, which shrinks along with reduced income and deteriorating health for older adults. Types of social support network include housing or living arrangement and social participation (Ren and Treiman, 2015). Yamaoka (2008) stresses the important role of the living arrangement in bringing family members together and considers it a vehicle for emotional support for members of the family. Research shows that living with immediate family members is a significant source for emotional benefits (Ren and Treiman, 2015). However, other studies show that it may affect individual's SW as tensions and conflicts may arise when family members live together (Rook, 1984).

Through social participation, individuals diversify their social connection and develop a sense of value and attachment and receive meaningful psychological support beyond the family network (Jothikaran et al., 2020; Yamaoka, 2008). Other studies document the positive association between social participation and happiness, especially with regard to older adults (Yamaoka, 2008). Social participation could be a deciding factor for SW, as one's social relationships and connection with surroundings are the key to one's healthy and active old age (Helliwell and Putnam, 2004).

Williamson (2010) confirms that safety and security and a good living environment are considered by older adults to be important for social well-being; where safety and security may include physical and emotional safety, financial security, and other kinds of security. The research confirms that feeling safe in the neighborhood is considered important for older adults, as good living environment is considered a reflection of security (Williamson, 2010).

Subjective health, which normally reflects a sense of perception of the assessment of physical condition, is strongly related to SW among older populations. Borg et al. (2008) finds that subjective measures of health have a significant effect on the social well-being compared to objective measures such as health care use. Research reports that poor physical health is related to lower subjective life satisfaction in later life; as old age has often been regarded as being related to subjective well-being due to reduced health; and that health is one of the key resources that shape SW of older adults (Bishop et al., 2006; Mroczek and Spiro, 2005).

Davies (2011) notes lifestyle such as physical activity as vital for promoting healthy aging and improve the QOL of the older adults. Golob et al. (2013) also confirms that regular and moderate physical activity is the key to one's healthy and active old age. The level of activity of the older adults is used by many researchers as a significant factor of happiness (Lawton, 1990). A review of studies on older 
adults shows that activities of daily living have been used to assess the functional capacity of community-living older adults (Suchy et al., 2011).

In short, few SW research has focused directly on variables such as happiness and life satisfaction (Saricam, 2005). Therefore, it is useful to investigate various relationships to better understand the interconnection of subjective happiness and life satisfaction.

\section{Theoretical Background and Conceptual Framework}

The survey used in this study covers all variables in the model (Fig. 1). The ADGSS looks beyond the functioning of the economic system of Abu Dhabi to consider more diverse experiences and living conditions of its adults and households. The general survey focuses on items that could capture and reflect aspects of life that matter to adults and that help shape the quality of their lives.

The hypothesized happiness framework recognizes Abu Dhabi adults' living conditions and well-being, as well as the resources (natural, social capital, economic, and human capital) that are needed to sustain such well-being. It is built on well-known initiatives for measuring well-being and sustainable development (Stiglitz et al., 2009). The unique feature of the current approach is measuring happiness utilizing several diverse features. The features include individuals themselves portraying the assessment of their own well-being outcomes. It features subjective interpretations of how they feel about their lives and happiness. In addition to

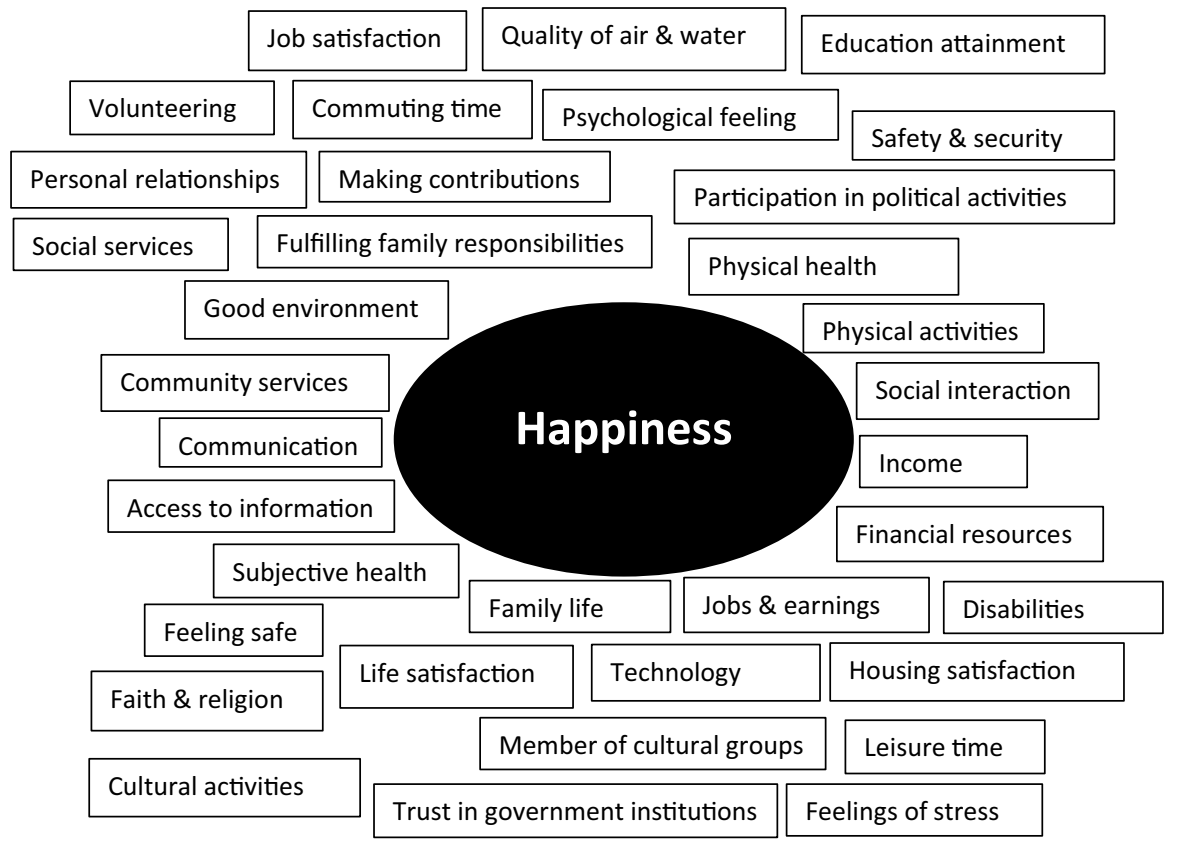

Fig. 1 Personal wellbeing framework as determinants of (happiness) 
some demographic factors, the issues are reflective of adults' subjective happiness as reflected by their living condition, health (health status, illness, functional ability), education, family and relations, social connection (family relationships, social involvement, and social relationships), the environment, psychological and mental feelings and attitude, work and jobs, physical activities, leisure time, and subjective life satisfaction.

\section{Objectives}

The objective of the study is to identify a path model to find the direct and indirect association of happiness with other determinants of social well-being for the older adults in Abu Dhabi in a systematic way. The hypotheses reflect the assumptions that happiness will correlate with other well-being variables (i.e. life satisfaction, subjective feelings, housing satisfaction, job satisfaction, relations with friends, activities and sports, getting along with family, leisure time, satisfaction with household income, subjective health perception, education attainment, and satisfaction with surrounding environment).

\section{Methodology}

\section{Study Sample and Instrument}

Based on many international social surveys including the OECD's Better Life, Gallup Global Well-being Survey, World Happiness Report, European Quality of Life Surveys, the ADGSS covers a variety of dimensions and factors that are thought to affect the well-being of residents in Abu Dhabi. Those dimensions include housing, household income and wealth, jobs and earnings, work-life balance, health, education and skills, personal safety and security, social and cultural values, social connections, civic engagement and governance, environmental quality, social and community services, access to information, and SW of happiness and life satisfaction.

The survey covered all regions of Abu Dhabi and all resident categories in Abu Dhabi. The survey was sent to residents in Abu Dhabi that were included in the large databases of public and private entities in Abu Dhabi. For workers residing in worker residential cities, a team of research assistants from the Statistics Center Abu Dhabi entered worker residential cities to collect responses using laptops. The survey distribution and collection took around three months. More than 51,000 Abu Dhabi residents replied to the online survey. A total of 1,004 respondents were 60 years or older (about $2.4 \%$ ), who are the target of this current research. The study focused on those 60 years and older. The main reason for selecting 60 years or older adults is that the official age of retirement in Abu Dhabi is 60 years. Some statistical difference tests were performed to compare those 60 years and older and other age segments below that age (i.e., 59, 58, and 57). The results did not change significantly, especially when we focus on the variable of happiness. 


\section{Methods and Analysis}

Since the questions on the survey instrument have different scales, data were standardized before performing further analysis. Given that the ADGSS contains more than 100 variables related to well-being, initial analysis was performed to reduce the list of variables affecting happiness. The initial analysis included individual correlation analysis and multiple regression to better understand the nature of the individual relationships between the factors.

A step-by-step path analysis was followed. At every step, one individual variable was introduced. At all instances, the happiness variable was treated as the dependent variable. Certain statistics were considered to keep the variable in the model or eliminate it completely. For each individual variable, three basic statistical values were considered, the magnitude of the standardized coefficient, the t-statistics, and the level of significance. The variables that did not reflect any significance were eliminated from further considerations. The path analysis aims to yield a path model and the estimates of associations, which can explain the pattern of association of happiness with other factors. The factors considered were not limited to those listed but included various other factors, including the number of family members, monthly rent, household expenses, working hours, commuting hours, feeling safe and protected, importance of religious and social commitments, trust in public institutions, satisfaction with drinking water, satisfaction with social sector services.

The overall fit statistics include Degrees of Freedom, Maximum Likelihood Ratio Chi-Square, Root Mean Square Error of Approximation (RMSEA), Normed Fit Index (NFI), Non-Normed Fit Index (NNFI), Comparative Fit Index (CFI), and Incremental Fit Index (IFI). In the final path analysis, for individual variables all significant relations were considered and included in the model.

Brief descriptions of the variables that remained to be considered in the final path model are given here. The variable asking respondents to describe their level of happiness as an Abu Dhabi resident using an 11-point scale (0 extremely unhappy to 10 extremely happy) is used as the dependent variable.

- The housing satisfaction variable was developed based on responses to the question 'How do you rate your overall satisfaction regarding your current residence?'

- The income satisfaction variable was based on the question 'Is your household able to make ends meet, namely, to pay for its usual necessary expenses?'

- The job satisfaction variable that remained in the analysis asked about the overall job satisfaction of the respondent.

- With regard to work, two variables remained and were computed based on the responses to the questions 'How many hours do you usually spend on leisure and personal care every day?' and 'In the past 12 months, how often has it been difficult to fulfill family responsibilities because of the amount of time you spent on your job?'

- Several health-related factors remained in the model. The first health variable is self- assessment of current health status, resulted from the question 'In general, how do you assess your current health status?' The frequency of doing 
sport variable was developed according to the question 'How often do you do sports?' The third health-related variable formed a composite outcome of four recent subjective feelings variables - feeling calm, feeling full of energy, feeling downhearted, and feeling rushed. To calculate the composite score, scores were reversed for the negatively worded variables.

- The education variable was computed based on the responses to the question 'What is the highest educational qualification that you have completed?'

- The safety and security variable that remained for further analysis was computed based on the responses to the statement 'In Abu Dhabi, I feel protected and safe'.

- Three social and family connection variables remained and were constructed based on the responses to the following questions or statements: 'In general, how well do you get along with everyone in your family?'; 'In general, I am satisfied with my family life'; and 'In general, I am satisfied with my relationships with other adults I know'.

- Three environment satisfaction variables remained and were constructed based on the responses to the following questions: 'How do you rate the level of air quality in your area of residence?'; 'Are you satisfied with the amount of parks, public gardens, or greenery in the area in which you live?'; and 'How do you feel about your current surrounding living environment?'

- Another SW variable that remained in the analysis was life satisfaction and was computed based on the responses to the question: 'From a scale of $0-10$, all things considered, how satisfied are you with your life as a whole nowadays?'

- Four variables that remained in the system were related to 'satisfaction with services for seniors and their families', 'satisfaction with services for adults with disabilities and their families', and 'satisfaction with parks and recreation facilities, water, sanitary sewer, streets, and sidewalks', based on which a composite variable was created to reflect the satisfaction with the surrounding area.

- The final variable was related to 'Access to Internet and Wi-Fi at home'.

The final path analysis model was identified as the best fit model given all fit statistics. Since LISREL was used in building the final model, several options in the software were utilized to arrive at the final model. The model only contained paths that were significant. All insignificant paths were removed from the final model. The software suggested adding new paths that would increase the fit of the model. A step-by-step analysis using this feature was utilized. This analysis provides estimates of decreases in Chi-square if new paths are added. Another option is suggestions for adding error covariance between variables. The software also provided largest negative standardized residuals between selected variables. Thus, many variables were eliminated from further analysis.

The covariance matrix of variables in the model is shown in Table 1. Looking at the matrix, it is interesting to note that the statistical distribution of the elements of a covariance matrix is not the same as that of a correlation matrix since the diagonal elements of a covariance matrix are the variances of the variables. These are random variables that vary from sample to sample. Values in the table show that variances for all the variables are relatively small (below 1.0); however, only two variables have variances above 1.0. 


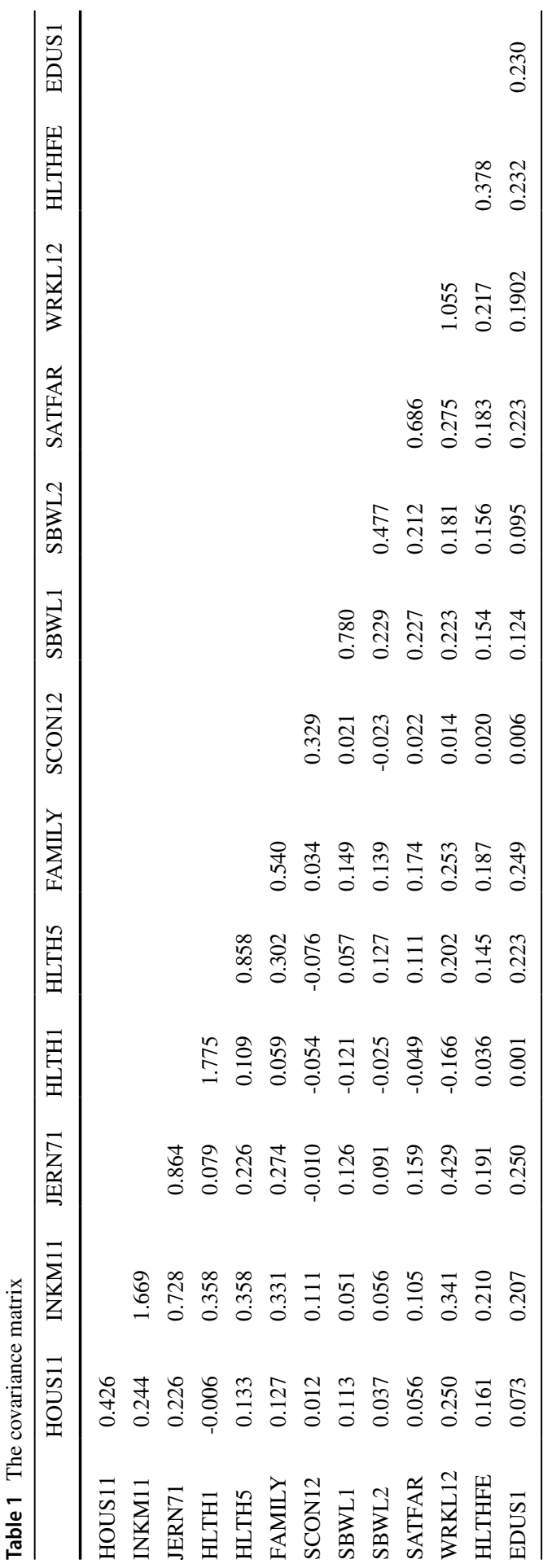


An important aspect of the path model is the illustration of the two following types of associations: direct and indirect. When a variable has an arrow directed toward the dependent variable, then it is said to be a direct association; when a variable has association with the dependent variable through another variable, then it is said to be an indirect association. To see the total association of a variable, we have to include both the direct and indirect related coefficients. One variable may not have a direct association, but it may have an indirect one.

\section{Results}

Table 2 provides some basic descriptive statistics and frequencies about the sample used. Significantly more male respondents got involved with the survey (78.3\% relative to $28.2 \%$ ). Non-UAE citizens constituted $71.2 \%$ relative to $28.8 \%$ UAE nationals. About $84.86 \%$ of the respondents were married, $7.17 \%$ single, and $7.97 \%$ divorced. With regard to the highest level of education attained, most respondents have a bachelor's degree $(33.54 \%$ ), followed by $17.88 \%$ master's degree holders, and $13.54 \%$ diploma holders. Most of the respondents $(75.13 \%)$ lived in the capital Abu Dhabi, 18.45\% in Al Ain, and 6.42\% in Al Dhafra.

LISREL 9.20 was used to estimate the path model for this study and analyze the ADGSS data set. There are several outcomes for this final model. After outlining the results of the final model, the variables that did not enter the final model will be outlined too. In addition, we will portray the variables that affected other variables, where there were arrows going out from them, but they were not influenced by any other variable with no arrows pointing at them. Model accuracy indicators and parameter values suggest that the final derived model structure is acceptable. As presented in Table 3, the final model yielded good fit indicators $\left(\chi^{2}=87.552\right.$ with 30 degrees of freedom, RMSEA $=0.0378, \mathrm{NFI}=0.9647$, $\mathrm{NNFI}=0.9605, \mathrm{CFI}=0.9788, \mathrm{GFI}=0.9867, \mathrm{IFI}=0.9783$, and $\mathrm{RMR}=0.0253$ ).

Table 2 Profile of respondents (60 years + )

\begin{tabular}{|c|c|c|c|c|c|c|c|}
\hline & Male & Female & & & & & \\
\hline \multirow[t]{2}{*}{ Gender } & $78.3 \%$ & $28.7 \%$ & & & & & \\
\hline & Married & Single & Divorced & & & & \\
\hline \multirow[t]{2}{*}{ Marital status } & $84.86 \%$ & $7.17 \%$ & $7.97 \%$ & & & & \\
\hline & $\begin{array}{c}\text { Below sec- } \\
\text { ondary }\end{array}$ & $\begin{array}{c}\text { Secondary } \\
\text { school }\end{array}$ & $\begin{array}{l}\text { Post high } \\
\text { school }\end{array}$ & Diploma & Bachelor & Master & Doctorate \\
\hline \multirow[t]{2}{*}{ Education } & $12.42 \%$ & $6.58 \%$ & $4.47 \%$ & $13.54 \%$ & $33.54 \%$ & $17.88 \%$ & $11.55 \%$ \\
\hline & Abu Dhabi & Al Ain & Al Dhafra & & & & \\
\hline \multirow[t]{2}{*}{ Location } & $75.13 \%$ & $18.45 \%$ & $6.42 \%$ & & & & \\
\hline & UAE & Non-UAE & & & & & \\
\hline Nationality & $29.8 \%$ & $71.2 \%$ & & & & & \\
\hline
\end{tabular}


Table 3 Goodness-of-fit statistics

\begin{tabular}{lc}
\hline Degrees of Freedom & 36 \\
\hline Maximum Likelihood Ratio Chi-Square & 87.552 \\
Root Mean Square Error of Approximation (RMSEA) & 0.0378 \\
Normed Fit Index (NFI) & 0.9647 \\
Non-Normed Fit Index (NNFI) & 0.9605 \\
Comparative Fit Index (CFI) & 0.9788 \\
Incremental Fit Index (IFI) & 0.9783 \\
Root Mean Square Residual (RMR) & 0.0253 \\
Goodness of Fit Index (GFI) & 0.9867 \\
\hline
\end{tabular}

Table 4 provides the outcomes of the final path model. The table shows the variables, the path direction, the estimates, the $t$-values, and their level of significance. It should be noted that all coefficients reflect a positive sign.

Figure 2 illustrates the overall path model where the focus is on older adult's happiness. Looking at the subjective happiness variable, we note significant direct association from seven different variables: leisure time, housing satisfaction, satisfaction with family life, satisfaction with relationships with other adults, life satisfaction, satisfaction with the surrounding environment, and recent subjective feelings. Recent subjective feelings, a composite of four types of feelings, produced the highest estimate $(0.3231)$, followed by satisfaction with household income (0.1940) and leisure time (0.1848).

Looking at Fig. 2, we note that a total of three variables did not receive any direct association with other variables. These three variables are recent subjective feelings, hours spent on leisure and personal care, and highest level of education attained. In other words, they only affected other variables. The three variables produced direct associations with many other variables.

The variable that is affected by the highest number of variables is subjective happiness with a total of eight variables. It is influenced directly by getting along with the family $(0.10)$, life satisfaction $(0.20)$, recent subjective feelings $(0.25)$, satisfaction with the surrounding environment $(0.17)$, leisure time $(0.12)$, housing satisfaction (0.11), frequency of doing sport (0.12), and relations with other friends $(0.11)$. The second ranked variable with the highest arrows pointing at it is housing satisfaction. It is influenced significantly by four different variables. These are recent subjective feelings (0.32), satisfaction with the surrounding environment (0.10), job satisfaction (0.14), and leisure time (0.14). The variable with the highest number of arrows pointing out from it is leisure time. It affects frequency of doing sport (0.10), housing satisfaction (0.14), subjective happiness $(0.12)$, satisfaction with household income $(0.12)$, and satisfaction with the surrounding environments (0.18).

Since the model considered many variables, it is interesting to see that a variety of those variables dropped out from final considerations. Table 5 summarizes the list of those variables that did not make it to the final model. We note that ten dimensions were affected. 


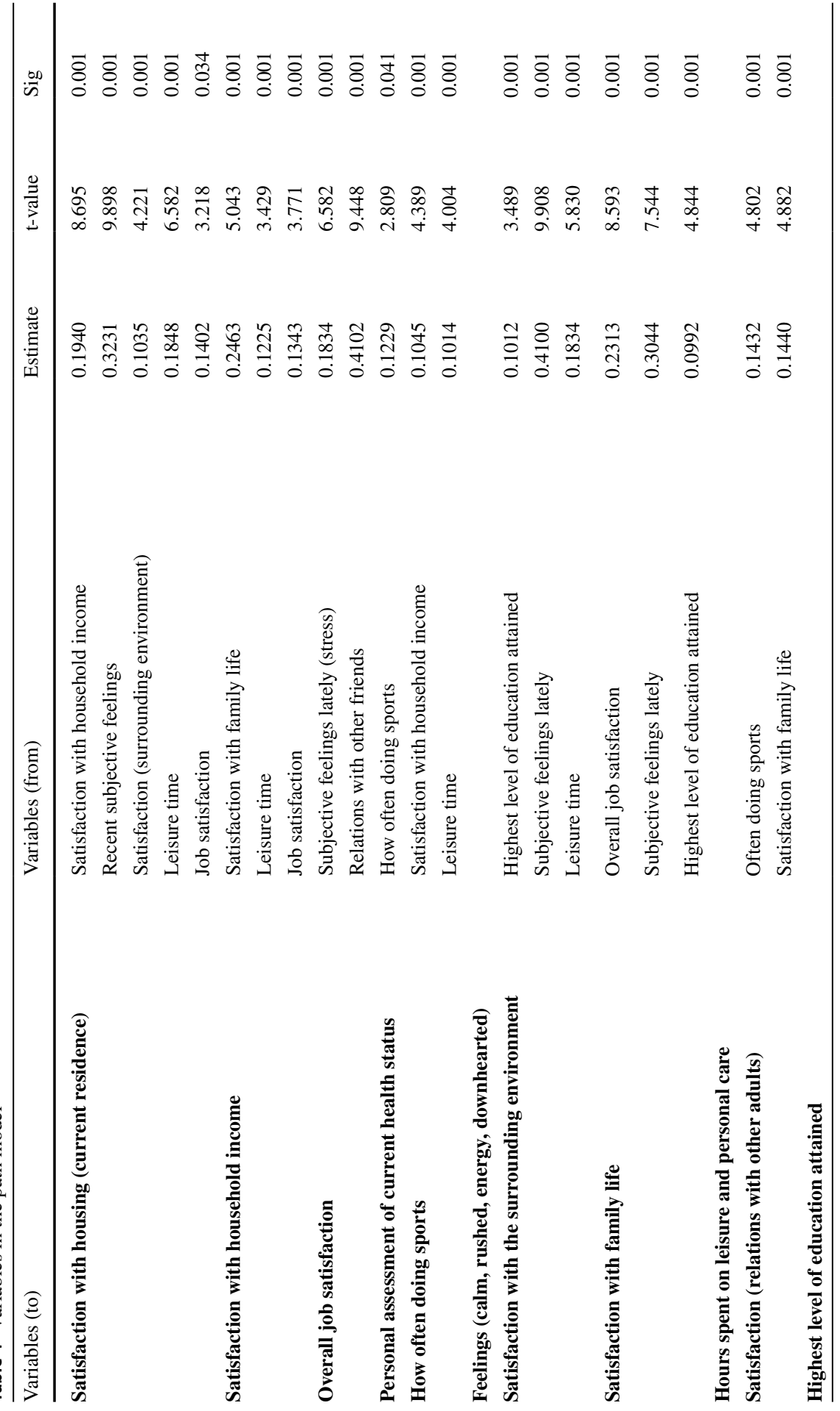




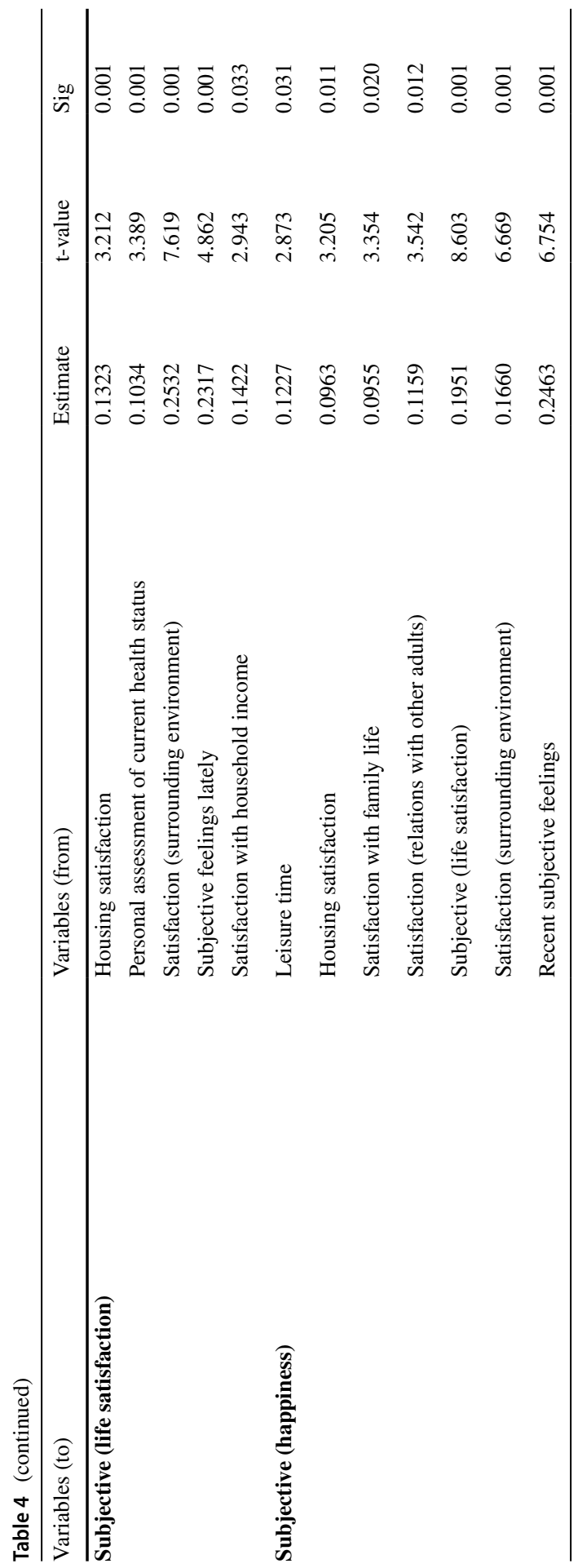




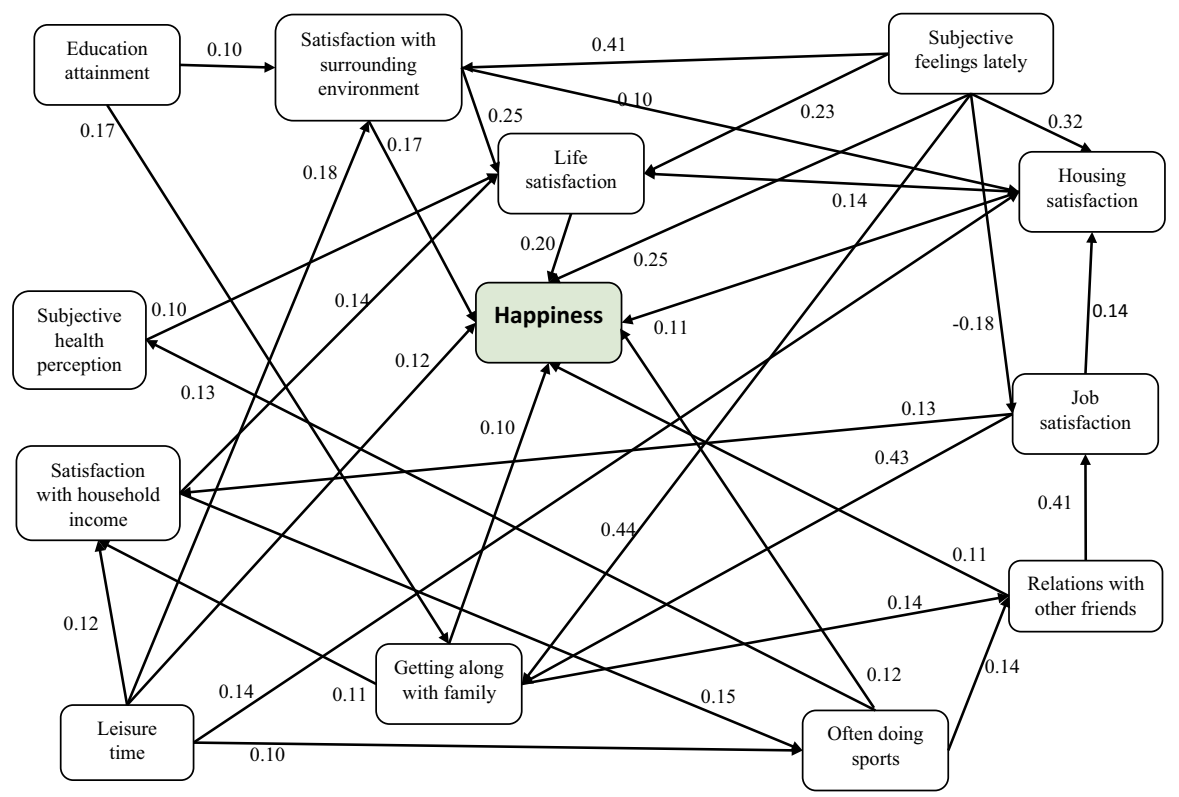

Fig. 2 The path model of statistical associations about older adult's happiness in Abu Dhabi - well-being factors

For the housing dimension, four variables were dropped: number of family members, monthly rent, monthly owner cost, and number of bedrooms. For the household income and wealth dimension, household expenses and ability to make ends meet were deleted. For jobs and earnings, length of unemployment and monthly income were dropped. For the work-life balance dimension, three variables were dropped: hours of work, commuting time to work, and how often has been difficult to fulfill responsibilities. For safety and security, four variables were eliminated: feeling protected and safe, feeling safe walking at night, feeling safe using the Internet, and having the ability to obtain rights. A total of nine variable dropped out of the social and culture values dimension, including cultural diversity in Abu Dhabi, feelings about the community, importance of religious commitment, importance of social commitments, participation in volunteering activities, perception of trust in adults, and feeling isolated. For the civic engagement and governance dimension, how often having a say in the community and trust in public institutions were dropped. For environmental quality dimension, three variables dropped out: satisfaction with drinking water, air quality, and park- and greenery-related areas. For the social and community services dimension, two dropped out: satisfaction with social sector services and ease of access to social services. Finally, for the access of information dimension, three variables dropped out: satisfaction with information access, personal level of knowledge about IT, and home access to Internet and Wi-Fi.

Table 6 shows the results of direct and indirect associations for all variables. The highest total association is exercised by recent subjective feelings (0.33571). As mentioned before, this variable is a composite of four feelings: feeling calm 
Table 5 Variables dropped out of the model during analysis

\begin{tabular}{|c|c|}
\hline Dimensions & Variables \\
\hline Housing & $\begin{array}{l}\text { Number of family members living with you } \\
\text { Monthly rent } \\
\text { Monthly owner cost } \\
\text { Number of bedrooms in the premises }\end{array}$ \\
\hline Household income and wealth & $\begin{array}{l}\text { Money used as household expenses } \\
\text { With income, able to make ends meet? }\end{array}$ \\
\hline Jobs and earnings & $\begin{array}{l}\text { If unemployed, how long? } \\
\text { If employed, monthly income from job }\end{array}$ \\
\hline Work-life balance & $\begin{array}{l}\text { How many hours do you usually work? } \\
\text { How long it takes you to get to work? } \\
\text { How often been difficult to fulfill responsibilities }\end{array}$ \\
\hline Health & All three variables entered the model \\
\hline Education and skills & The variable entered the model \\
\hline Safety and security & $\begin{array}{l}\text { I feel protected and safe } \\
\text { I feel safe walking at night } \\
\text { I feel safe using the internet } \\
\text { I have the ability to obtain rights through legal channels }\end{array}$ \\
\hline Social and culture values & $\begin{array}{l}\text { There is cultural diversity in Abu Dhabi } \\
\text { Your level of awareness about cultural events and venues } \\
\text { Feelings about the Emirati community } \\
\text { The importance of (religious commitment) } \\
\text { The importance of (other social commitments) } \\
\text { Participation in voluntary activities } \\
\text { How many adults can support you (if needed) } \\
\text { Self-opinion that adults could be trusted } \\
\text { During last } 4 \text { weeks, have you felt isolated? }\end{array}$ \\
\hline Social connection & Both variables entered the model \\
\hline Civic engagement and governance & $\begin{array}{l}\text { How often do you feel you have a say in your community? } \\
\text { Trust in institutions (Health, education, police, courts, and media)? }\end{array}$ \\
\hline Environment quality & $\begin{array}{l}\text { Satisfaction with quality of drinking water } \\
\text { Satisfaction with air quality } \\
\text { Satisfaction with parks, public gardens, green areas }\end{array}$ \\
\hline Social and community services & $\begin{array}{l}\text { Satisfaction with social sector services } \\
\text { Easy access to social service providers }\end{array}$ \\
\hline Access to information & $\begin{array}{l}\text { Satisfaction with access to needed information } \\
\text { My level of knowledge about IT } \\
\text { Home access to internet and Wi-Fi }\end{array}$ \\
\hline Subjective well-being & Both variables entered the model \\
\hline
\end{tabular}


Table 6 Type of associations on subjective happiness

\begin{tabular}{lllll}
\hline Code & Variables & $\begin{array}{l}\text { Direct } \\
\text { associa- } \\
\text { tion }\end{array}$ & Indirect association & Total association \\
\hline SBWL1 & Subjective life satisfaction & 0.20 & - & \\
HLTHFE & Psychological feelings lately & 0.25 & 0.08571 & 0.20121 \\
HOUS11 & Satisfaction with housing & 0.11 & 0.02842 & 0.33571 \\
JERN71 & Job satisfaction & - & 0.06232 & 0.13811 \\
SCON12 & Relations with others (friends) & 0.11 & 0.06477 & 0.06232 \\
HLTH5 & Often doing sports & 0.12 & 0.08163 & 0.17475 \\
FAMILY & Relations (getting along) with family & 0.10 & 0.01771 & 0.20163 \\
INKM11 & Satisfaction with household income & - & 0.04845 & 0.11774 \\
SATFAR & Satisfaction with surrounding environ- & 0.17 & 0.08911 & 0.04845 \\
& ment & & & 0.25911 \\
HLTH1 & Subjective health perception & - & 0.02044 & 0.02044 \\
EDUS1 & Education attainment & - & 0.03933 & 0.03933 \\
WRKL12 & Leisure time & 0.12 & 0.01354 & 0.13354 \\
\hline
\end{tabular}

and peaceful, having lots of energy, feeling downhearted and depressed, and feeling rushed or pressed for time. These are short term feelings that reflect the influence of recent circumstances. The second highest direct association is coming from satisfaction with the surrounding environment (0.25911). The third factor with highest total association is frequency of doing sport (0.20163). Reflecting satisfaction with longer term associations, the variable subjective life satisfaction also provided a high total coefficient of 0.20121. It is interesting to note that life satisfaction exerted high indirect associations. The results also show that four variables influenced happiness indirectly with no direct associations noticeable: job satisfaction, satisfaction with household income, subjective health perception, and highest level of education attainment.

Analysis of variance shows some statistical differences between males and females when it comes to subjective happiness. With an F-value of 4.220, which is significant at the 0.04 level, female elderlies portray a happiness level of 7.47 with a standard deviation (SD) of 2.755, compared to 7.92 with an SD of 2.271 for males. Concerning the highest level of education attained, the highest subjective happiness is observed with regard to those with a bachelor's degree (mean of 8.17 with SD of 1.748), and the lowest of 7.22 with SD of 3.635 for those below secondary school. With regard to marital status, we also get significance with an F-value of 15.383 significant at the 0.001 level. The married individuals recorded a mean of 8.02 with $2.008 \mathrm{SD}$. The singles recorded a mean of 7.11 with $2.852 \mathrm{SD}$. The divorced recorded a mean of 6.37 with $3.934 \mathrm{SD}$. 


\section{Discussions}

The purpose of this study was to examine and provide a basis for understanding the path structure of the happiness factors for older adults in Abu Dhabi. Our study differs from other similar studies in terms of the methods used and variables included. We examined the path structure and relationships between many variables and happiness. We obtained a good fit of the final overall model after some modifications.

The highest total association was observed with regard to recent subjective feelings with an overall 0.33571 coefficient. Our results are consistent with the notion of envisioning happiness to be present-oriented, while life satisfaction is more past oriented (Stock et al., 1986). For seniors, happiness is associated more with current positive and negative feelings as portrayed by other studies (Lima et al., 2012; Chou and Chi, 1999).

Relative to other research on life satisfaction, the results also suggest that life satisfaction reflected the net of positive affect over negative affect, appropriately weighted by intensity but assessed over all life domains, associated with the past. The main variables that directly affected life satisfaction included housing satisfaction, health assessment, satisfaction with household income, and satisfaction with the surrounding environment. Variables that have a short-term denotation such as recent subjective feelings also affected life satisfaction directly.

Satisfaction with the surrounding environment provided a significant high influence on happiness. Many studies attest the importance of the functional capacity in community-living older adults (Suchy et al., 2011). The results of this study thus call for promoting the SW of older adults through addressing environmental challenges as a major contributor to happiness of older adults (Lima et al., 2012).

Family life and getting along with the family and relations with other friends had direct association on happiness and many other variables in the model. The results are in agreement with other studies that reflect the importance of social support or interaction within a social network of family members and friends in creating more a positive feeling of SW (Rakowski et al., 2003; Ren and Treiman, 2015). Many studies also acknowledge that the living arrangement is an individual-level social capital that bonds family members together (Yamaoka, 2008). Emotional well-being could be highly supported by emotional support from family members and friends. Such direct associations enforce the notion that living with immediate family members is a significant source of emotional benefits, as suggested by Ren and Treiman (2015).

The results of this present research are in line with other studies that document the positive association between social participation and happiness, especially regarding older adults (Yamaoka, 2008). The results are also consistent with Golob et al. (2013), which confirms that one's social relationships and connection with one's surroundings are the key to one's healthy and active old age. Our results are supported by other studies conducted in different cultures showing 
that social support or interaction plays a major role in more positive feeling of SW (Rakowski et al., 2003). It should be noted that empirical research shows that aging is often associated with a shrinking social network, reduced income, and deteriorating health (Wallace and Pichler, 2009).

Variables that exerted a combination of direct and indirect influences through other variables on happiness included leisure time, often doing sports, and subjective health assessment. Many other studies also capture the significance of these variables as major causes for better life satisfaction for older adults in general (Godfrey and Johnson, 2009). The level of physical activity for older adults is addressed by many studies as a significant factor of happiness (Suchy et al., 2011). In addition, this research shows that self-assessment of health status was influenced by one variable only - frequency of doing sports. The relationships between the two variables are also noted by other empirical research (Golob et al., 2013).

It is interesting to note that in the context of Abu Dhabi both income and job satisfaction had no direct association on happiness of older adults. Both however appear to be significant contributors to happiness in some other societies or cultures (Ergin and Mandiracioglu, 2015; Pan and Zhou, 2013). Empirical research also indicates a positive relationship between having a full-time job and the well-being of older adults (Morrow-Howell et al., 2003). In the present study, the job satisfaction variable had an indirect association on both happiness and life satisfaction. Checking the data further, we see that $58 \%$ in the sample said that they still work full time and $6 \%$ are involved in part-time employment. The income variable had an indirect association with happiness but a direct association with life satisfaction. This may suggest that working is still a priority in older adult's life in Abu Dhabi and that perhaps job satisfaction means the same for older adults as for the younger working population. Moreover, the study shows positive coefficients in the path analysis model between job satisfaction and other variables reflecting getting along with family variable.

\section{Conclusions}

Overall, the results of this present study show that older adults' happiness is affected by many interconnected variables that have a major role in shaping their SW. As the well-being of older adults in Abu Dhabi is an important objective for both economic and health policy, this study has significant policy implications for Abu Dhabi.

For policy makers, it is important to comprehend that a multi-dimensional and integrated happiness policy framework for older adults should be adopted. While the happiness of older adults in Abu Dhabi could be enhanced by focusing on certain life and social variables identified in this research, policy makers could also benefit from this research on how to integrate various polices to achieve a high level of synergy. Policy bundles covering housing, family relationships, income support, health and physical activity promotion, and psychological counselling are more likely to work better towards enhancing older adult's happiness than individual policy being implemented separately. In addition, this study highlights the importance of involving older adults in decision-making for major policy decisions over housing, 
income, and social support. Furthermore, the results emphasize the importance of better understanding older persons' expectations and how these expectations are interconnected.

\section{Implications}

The originality of the current research reflects itself in studying the well-being of old adults through a holistic model that include a comprehensive list of variables. Many related studies in the extant literature, for example, did not include the factor of job satisfaction as a dominant factor when it comes to the happiness of seniors.

The ADGSS has provided valuable information about different categories of population in Abu Dhabi. Testing differences according to gender, education attainment, and marital status can provide insights for future studies that employ multi-level analysis instead of simple path analysis. Such analysis is useful for policy makers to better understand the nature of the differences between the Abu Dhabi population categories. The resulting information could be used in developing significant initiatives and policies with regard to the social system. The current use of path analysis provided a model with a good fit. However, future research should account for the hierarchical structures of Abu Dhabi's diverse population.

It should also be pointed out that the study focused on older adults $(60+)$ given that the retirement age in Abu Dhabi is 60 years. Future surveys should further break down the $60+$ age category to provide more details for the older age segments.

\section{Declarations}

Conflict of interest The authors certify that they have no affiliations with or involvement in any organization or entity with any financial interest (such as honoraria; educational grants; participation in speakers' bureaus; membership, employment, consultancies, stock ownership, or other equity interest; and expert testimony or patent-licensing arrangements), or non-financial interest (such as personal or professional relationships, affiliations, knowledge or beliefs) in the subject matter or materials discussed in this manuscript.

Informed Consent None.

Ethical Treatment of Experimental Subjects (Animal and Human) None.

Open Access This article is licensed under a Creative Commons Attribution 4.0 International License, which permits use, sharing, adaptation, distribution and reproduction in any medium or format, as long as you give appropriate credit to the original author(s) and the source, provide a link to the Creative Commons licence, and indicate if changes were made. The images or other third party material in this article are included in the article's Creative Commons licence, unless indicated otherwise in a credit line to the material. If material is not included in the article's Creative Commons licence and your intended use is not permitted by statutory regulation or exceeds the permitted use, you will need to obtain permission directly from the copyright holder. To view a copy of this licence, visit http://creativecommons.org/ licenses/by/4.0/. 


\section{References}

Anand, P., Durand, M., \& Heckman, J. (2011). The measurement of progress - Some achievements and challenges. Journal of the Royal Statistical Societies, 174, 851-855.

Bakker, A., \& Oerlemans, W. (2011). Subjective well-being in organizations. In K. S. Cameron \& G. M. Spreitzer (Eds.), The Oxford Handbook of Positive Organizational Scholarship (pp. 178-189). Oxford University Press.

Bishop, A., Martin, P., \& Poon, L. (2006). Happiness and congruence in older adulthood: A structural model of life satisfaction. Aging and Mental Health, 10(5), 445-453.

Blanchflower, D., \& Oswald, A. (2008). Is well-being U-shaped over the life cycle? Social Science and Medicine, 66(8), 1733-1749.

Blood, I., \& Bamford, S. (2010). Equality and diversity and older adults with high support needs. York: Joseph Rowntree Foundation.

Borg, C., Fagerström, C., Balducc, C., Burholt, V., Ferring, D., Weber, G., \& Hallberg, I. (2008). Life satisfaction in 6 European Countries: The relationship to health, self-esteem, and social and financial resources among adults (aged 65-89) with reduced functional capacity. Geriatric Nursing, 29(1), 48-57.

Brülde, B. (2007). Happiness theories of the good life. Journal of Happiness Studies, 8(1), 15-49.

Bye, D., \& Pushkar, D. (2009). How need for cognition and perceived control are differentially linked to emotional outcomes in the transition to retirement. Motivations and Emotions, 33, 320-332.

Campbell, A. (1981). The sense of well-being in America. McGraw-Hill.

Chaudhury, H., \& Oswald, F. (2019). Advancing understanding of person-environment interaction in later life: One step further. Journal of Aging Studies, 51.https://doi.org/10.1016/j.jaging.2019. 100821

Chekola, M. (2007). Happiness, rationality, autonomy and the good life. Journal of Happiness Studies, 8, 51-78.

Cheng, S., \& Chan, A. (2006). Filial piety and psychological well-being in well older Chinese. The Journals of Gerontology Series B Psychological Sciences and Social Sciences, 61(5), 262-269.

Chou, K \& Chi, I. (1999) Determinants of life satisfaction in Hong Kong Chinese elderly: A longitudinal study, Aging \& Mental Health, 3:4, 328-335. https://doi.org/10.1080/13607869956109

Clark, A., \& Oswald, A. (1994). Unhappiness and unemployment. The Economic Journal, 104(424), $648-659$.

Cummins, R. (1996). The domains of life satisfaction: An attempt to order chaos. Social Indicators Research, 38, 303-328.

Davies N. (2011). Promoting healthy ageing: the importance of lifestyle. Nursing Standard, 25, (19), 43-49. Quiz 50. https://doi.org/10.7748/ns2011.01.25.19.43.c8270. PMID: 21287926

Diener, E., Oishi, S., \& Lucas, R. (2003). Personality, culture, and subjective well-being: Emotional and cognitive evaluations of life. Annual Review Psychology, 54, 403-425.

Diener, E., Wirtz, D., Tov, W., Kim-Prieto, C., Choi, D., Oishi, S., \& Biswas-Diener, R. (2009). New measures of well-being: Flourishing and positive and negative feelings. Social Indicators Research, 39, 247-266.

Dolan, P., Peasgood, T., \& White, M. P. (2008). Do we really know what makes us happy? A review of the economic literature on the factors associated with subjective well-being. Journal of Economic Psychology, 29, 94-122.

Dong, H., Larsson, B., Dragioti, E., Bernfort, L., Levin, L., \& Gerdle, B. (2020). Factors associated with life satisfaction in older adults with chronic pain (PainS65+). Journal of Pain Research, 13, 475-489.

Ergin, I., \& Mandiracioglu, A. (2015). Inequalities for self-rated health and happiness in Turkish elderly: World Values Survey 1990-2013. European Journal of Public Health, 25.https://doi.org/ 10.1093/eurpub/ckv176.140

Farahani, M., Dorri, S., \& Seyedfatemi, N. (2020). Happiness strategies for older adults: A qualitative study. Research in Gerontological Nursing, 13(5), 254-263. https://doi.org/10.3928/1940492120200220-02

Gao, Y. J. (2018). Functional autonomy, emotional support, and well-being trajectories among the old-old. International Journal of Psychology \& Behavior Analysis, 4, 137. https://doi.org/10. 15344/2455-3867/2018/137 
George, L. (1979). The happiness syndrome: Methodological and substantive issues in the study of social-psychological well-being in adulthood. The Gerontologist, 19, 210-216.

Gerstorf, D., Lovden, M., Rocke, C., Smith, J., \& Lindenberger, U. (2007). Well-being affects changes in perceptual speech in advanced old age: Longitudinal evidence for a dynamic link. Developmental Psychology, 43, 705-718.

Godfrey, M., \& Johnson, O. (2009). Digital circles of support: Meeting the information needs of older adults. Computers in Human Behavior, 25(3), 633-642.

Golob, M., Giles, A., \& Rich, K. (2013). Enhancing the relevance and effectiveness of water safety education for ethnic and racial minorities. International Journal of Aquatic Research and Education, 7(1), 39-55.

Gwozdz, W., \& Sousa-Poza, A. (2010). Ageing, health and life satisfaction of the oldest old: An analysis for Germany. Social Indicators Research, 97, 397-417.

Helliwell, J., \& Putnam, R. (2004). The social context of well-being. Philosophical Transactions-Royal Society of London Series B, 359, 1435-1446.

Herero, V., \& Extremera, N. (2010). Daily life activities as mediators of the relationship between personality variables and subjective well-being among older adults. Personality and Individual Differences, 49, 124-129.

Inal, S., Subasi, F., Ay, S., \& Hayran, O. (2007). The link between health-related behaviors and life satisfaction in elderly individuals who prefer institutional living. BMC Health Services Research, 7, 30-37.

Jothikaran, E., Meershoek, A., \& Krumeich, A. (2020). Older adults in traditional and modern living arrangements in southern India: The importance of maintaining a sense of belonging and positive intergenerational exchanges. Journal of Aging Studies, 54.https://doi.org/10.1016/j.jaging.2020. 100867

Kudo, H., Izumo, Y., Kodama, H., Watanabe, M., Hatakeyama, R., Fukuoka, Y., \& Sasaki, H. (2007). Life satisfaction in older adults. Geriatrics and Gerontology International, 7, 15-20.

Lawton, M.P. (1990). Aging and Performance of Home Tasks. Human Factors, 32(5), 527-536. https:// doi.org/10.1177/001872089003200503

Lima, M., Barros, M., \& Alves, M. (2012). Happiness in the elderly: An epidemiological approach in the ISA Camp 2008 study. Cad Saúde Pública, 28(12), 2280-2292.

Lopez, F., \& Rice, K. (2006). Preliminary development and validation of a measure of relationship authenticity. Journal of Counseling Psychology, 53, 362-371.

Lucas, R. E., Diener, E., \& Suh, E. M. (1996). Discriminant validity of well-being measures. Journal of Personality and Social Psychology, 71, 616-628.

Lyubomirsky, S., Sheldon, K., \& Schkade, D. (2005). Pursuing happiness: The architecture of sustainable change. Review of General Psychology, 9, 111-131.

Massey, B., Edwards, A., \& Musikanski, L. (2020). Life satisfaction, affect, and belonging in older adults. Applied Research in Quality of Life. https://doi.org/10.1007/s11482-019-09804-2

Menec, V. (2003). The relation between everyday activities and successful aging: A 6-year longitudinal study. The Journals of Gerontology Series B Psychological Sciences and Social Sciences, 58, 74-83.

Morrow-Howell, N., Hinterlong, J., \& P. R., \& Tang, F. (2003). Effects of volunteering on the well-being of older adults. Journals of Gerontology, Series B Psychological Sciences and Social Sciences, 58, 137-145.

Mroczek, D., \& Sprio, A. (2005). Change in life satisfaction during adulthood: Findings from the Veterans Affairs Normative Aging Study. Journal of Personality and Social Psychology, 1, 189-202.

Myers, D. (2013). Psychology. Worth Publishers.

Oishi, S., Diener, E., Lucas, R., \& Suh, E. (1999). Cross-cultural variations in predictors of life satisfaction: Perspectives from needs and values. Personality and Social Psychology Bulletin, 25, 980-990.

Pan, J., \& Zhou, W. (2013). Can success lead to happiness? The moderators between career success and happiness. Asia Pacific Journal of Human Resources, 51.https://doi.org/10.1111/j.1744-7941.2012. 00033.x

Parra-Rizo, M., \& Sanchis-Soler, G. (2020). Satisfaction with life, subjective well-being and functional skills in active older adults based on their level of physical activity practice. International Journal of Environmental Research and Public Health, 17(4), 1299. https://doi.org/10.3390/ijerph17041299

Pavot, W., \& Diener, E. (2008). The satisfaction with life scale and the emerging construct of life satisfaction. The Journal of Positive Psychology, 3(2), 137-152. 
Peterson, C., Ruch, W., Beermann, U., Park, N., \& Seligman, M. (2007). Strengths of character, orientations to happiness, and life satisfaction. Journal of Positive Psychology, 2, 149-156.

Pinquart, M., \& Sørensen, S. (2000). Influences of socioeconomic status, social network, and competence on subjective well-being in later life: A meta-analysis. Psychology and Aging, 15(2), 187-224.

Rakowski, W., Clark, M., Miller, S., \& Berg, K. (2003). Successful aging and reciprocity among older adults in assisted living settings. In L. W. Poon, S. H. Gueldner \& B.M. Sprouse (Eds.), Successful aging and adaptation with chronic diseases. New York: Springer Publishing.

Ren, Q., \& Treiman, D. (2015). Living arrangements of the elderly in China and consequences for their emotional well-being. Chinese Sociological Review, 47(3), 255-286.

Rey, L., Extremera, N., \& Pena, M. (2011). Perceived emotional intelligence, self-esteem and life satisfaction in adolescents. Psychosocial Intervention, 20(2), 227-234.

Rook, K. (1984). The negative side of social interaction: Impact on psychological well-being. Journal of Personality and Social Psychology, 46(5), 1097-1108.

Saricam, H. (2005). Life satisfaction: Testing a structural equation model based on authenticity and subjective happiness. Polish Psychological Bulletin, 46(2), 278-284.

Steptoe, A., Deaton, A., \& Stone, A. (2014). Subjective well-being, health, and ageing. The Lancet. https://doi.org/10.1016/S0140-6736(13)61489-0

Stiglitz, J., Sen, A. \& Fitoussi, J. (2009). Report by the Commission on the Measurement of Economic Performance and Social Progress (CMECSP). Retrieved from https://www.researchgate.net/publication/ 258260767_Report_of_the_Commission_on_the_Measurement_of_Economic_Performance_and_ Social_Progress_CMEPSP

Stock, W., Okun, M., \& Benin, M. (1986). The structure of subjective well-being among the elderly. Psychology and Aging, 1, 91-102.

Suchy, Y., Kraybill, M., \& Franchow, E. (2011). Practice effect and beyond: Reaction to novelty as an independent predictor of cognitive decline among older adults. Journal of the International Neuropsychological Society, 17(1), 101-111.

Tellaa, R., Haisken-De Newc, J., \& MacCulloch, R. (2010). Happiness adaptation to income and to status in an individual panel. Journal of Economic Behavior \& Organization, 76, 834-852.

Tkatch, R., Wicker, E., \& Martin, D. (2018). Aging strong 2020: Improving the health and well-being of older adults. Innovation in Aging, 2(1), 240. https://doi.org/10.1093/geroni/igy023.897

Valois, R., Paxton, R., Zullig, K., \& Huebner, E. (2006). Life satisfaction and violent behaviors among middle school students. Journal of Child and Family Studies, 15, 695-707.

Veenhoven, R. (2009). How do we assess how happy we are? In A. K. Dutt \& B. Radcliff (Eds.), Happiness, economics and politics: Towards a multi-disciplinary approach (pp. 45-69). Edward Elger Publishers.

Wallace, C., \& Pichler, F. (2009). More participation, happier society? A comparative study of civil society and the quality of life. Social Indicators Research, 93(2), 255-274.

Williamson, T. (2010). My name is not dementia: Adults with dementia discuss quality of life indicators. Alzheimer's Society.

Yamaoka, K. (2008). Social capital and health and well-being in East Asia: A population-based study. Social Science \& Medicine, 66(4), 885-899.

Publisher's Note Springer Nature remains neutral with regard to jurisdictional claims in published maps and institutional affiliations.

Muna Albahar is a professor at the United Arab Emirates. She is also an Advisor to the Chairman of the Abu Dhabi Community Development, and Head of the Social Monitoring System.

Masood Badri is a professor at the United Arab Emirates University, seconded to the Abu Dhabi Abu Dhabi Department of Community Development, UAE, as Advisor to the Chair, and the Head of Research. He has published widely in academic journals.

Mugheer Al Khaili is the Chairman of the Abu Dhabi Department of Community Development, UAE and member of the Executive Committee at the Government of Abu Dhabi. He has published widely in academic journals. 
Fahad Al Neyadi is the Vice Chairman of the Abu Dhabi Department of Community Development, UAE. He has published widely in academic journals.

Guang Yang is the research program manager at the Abu Dhabi Department of Community Development, UAE. His current research interests include quality of life, wellbeing, education policy, student engagement, parent involvement, and teacher effectiveness.

Asma Al Rashedi is the research senior specialist, at the Abu Dhabi Department of Community Development, UAE. She has a wide experience of working on social statistics, artificial intelligence, educational statistics, survey development and implementation, and large-scale student assessment.

\section{Authors and Affiliations}

\section{Muna Al Bahar ${ }^{1,2} \cdot$ Masood Badri, $^{1,3} \cdot$ Mugheer Al Khaili $^{3} \cdot$ Fahad Al Neyadi $^{2}$. Guang Yang ${ }^{2}$. Asma Al Rashdi ${ }^{2}$}

Muna Al Bahar

Muna.Albahar@DCD.AbuDhabi.ae

Mugheer Al Khaili

Mugheer@DCD.AbuDhabi.ae

Fahad Al Neyadi

falneyadi@DCD.AbuDhabi.ae

Guang Yang

Guang.yang@adek.AbuDhabi.ae

Asma Al Rashdi

Asma.Alrashedi@adek.AbuDhabi.ae

1 UAE University, Abu Dhabi, UAE

2 Abu Dhabi Department of Community Development, Abu Dhabi, UAE

3 Research and Social Monitoring, Abu Dhabi Department of Community Development, Abu Dhabi, UAE 